\title{
Feasibility of mini combined cycles for naval applications
}

\author{
Dario Barsi ${ }^{1}$, Carlo Costa $^{1}$, Francesca Satta ${ }^{1}$, Pietro Zunino ${ }^{1,{ }^{*}}$, and Vitaly Sergeev ${ }^{2}$ \\ ${ }^{1}$ Dipartimento di Ingegneria Meccanica, Energetica, Gestionale e dei Trasporti, Università degli Studi \\ di Genova, Genova, Italy \\ ${ }^{2}$ Institute of Power and Transport Systems, Peter the Great Saint Petersburg Polytechnic University, \\ Saint Petersburg, Russia
}

\begin{abstract}
The objective of energy production with low environmental impact will have, in the near future, high potential of development also for naval applications. The containment of pollutant emissions can be achieved by the combined use of an innovative mini gas-steam combined cycle with thermal energy cogeneration to feed the ship thermal utilities, in place of the current Diesel engine application, and liquefied natural gas as fuel (LNG). The present work is focused on the definition of the architecture of the plant, by selecting optimal distribution of pressure and temperature and repartition of power between Gas Turbine (GT), Steam Turbine (ST) and thermal utilities, as well as on the choice and sizing of the individual components. The main purpose is the definition of a compact, high efficiency, system. The proposed basic mini-cycle ranges from $2 \mathrm{MW}$ to $10 \mathrm{MW}$ electric power. Thanks to the combined heat and power cogeneration plant adopted, for an overall electrical efficiency of about $30 \%$, a total return (thermal + electricity) of about $75 \%$ can be achieved. An example of plant providing large power, in a partially modular arrangement is also proposed.
\end{abstract}

\section{Introduction}

In the shipbuilding sector, a great effort is made to achieve a significant reduction of the pollutant emissions produced by the engines used for the generation of electric and thermal energy on board of the ships. The need for reduction of ship emissions arises from the necessity of respecting the restrictive limits imposed by the International Maritime Organization (IMO) and from the growing of Emission Control Areas (ECAS), forbidden for the ships that do not respect the limitations.

The technology of the combined plants is already widely used in the production of electricity worldwide. Combined heat and power (CHP) plants are capable of reducing the amount of fuel required to produce given amounts of electricity and heat as compared with that required by separate generation systems. The most commonly used combined cycle power plant includes a gas turbine engine as a topping cycle, a heat recovery steam generator (HRSG) and a steam turbine as bottoming cycle. Downstream of the gas turbine cycle high

*Corresponding author: pietro.zunino@unige.it 
temperature thermal energy (usually in the range $500-600^{\circ} \mathrm{C}$ ) is available to produce useful heat. For inland applications, combined cycles based on a heavy duty gas turbine and a steam turbine have a high thermodynamic efficiency, which can reach up to $60 \%$ for maximal loads [1]. In recent years, combined systems based on gas turbines have also started to be used on board the ships, to fulfil the energetic requests of ships, which include the need for propulsive, electrical (hotel load), and thermal power. In the last decades, they have been especially used as auxiliary power units in large cruise vessels. However, the solutions with gas turbines as prime movers, are up to now, more widely employed in the area of military shipping, whereas they are slowly penetrating some parts of the naval commercial market, particularly in two categories of commercial vessels: the fast ferries and the cruise liners [2]. These systems, which are able to satisfy the whole of the ship's energy needs by an integrated energy system, in marine industry notation are usually being referred to as COGES (COmbined Gas turbine Electric and Steam) plants, when an electric propulsion system (propulsion units coupled to electric motors) is adopted for increased modularity and better utilization of machinery space. A COGES system is used in the Millenium ship, which is the world's first gas-turbine powered cruise ship [3]. However, these systems are expected to penetrate more and more in the naval commercial sector as many favourable issues are going to convince the ship owners to use gas turbines rather than diesel engines in new built ships. The main issues are associated with the large power-to-weight ratios of gas turbines, the compactness and weight saving and the possibility of working with clean fuels like liquid natural gas (LNG).

The use of LNG for the gas turbine feeding allows the substantial elimination of SOx and particulate emissions and a strong reduction of the unburned hydrocarbons (UHC) as well as of NOx emissions. In addition, the application of combined cycles with heat recovery increases the efficiency of the plant and consequently reduces $\mathrm{CO} 2$ emissions, which are further reduced due to the low number of carbon atoms of the LNG, respect to the traditional marine fuels. Thanks to the positive factors associated with COGES plants, a number of studies focused on the design and optimization of marine energy systems, which employ this technology for large ship applications, can be found in the recent literature [4-7]. However, this technology is mature as far as large power plants are concerned, but not for the smaller ones. These latter can be based on the one stage centrifugal compressor-centripetal uncooled turbine compact architecture which is normally used in micro gas turbine systems. Very few examples of mini power plants can be found in literature. Salvini et al. in their study [8] showed that GT based small CHP plants in the range 1.5-6 $\mathrm{MW}_{\mathrm{el}}$ can lead to relevant cost savings, while for smaller sizes the investment effectiveness has to be carefully checked. Brostmeyer in his patent [9] describes a mini power plant, able to produce affordable electricity at around $\$ 1,500$ per $\mathrm{kW}$, providing $5.5 \mathrm{MW}$ of electricity plus 3.8 MW of heat.

Based on the aforementioned premises, a mini sized power plant can find different applications in the naval field, not only as the prime mover of small size vessels, but also to be adopted in modular solutions for larger applications. This modular concept can be used also for overcoming the efficiency drop occurring in gas turbines when the loading is strongly reduced, or to fulfil the need for redundancy on board, or again as auxiliary apparatus in large vessels for particular operating conditions. Indeed, the mini combined heat and power plant can be designed to satisfy the thermal request not only of small size, but also of larger size vessels.

The present paper is focused on the definition of an innovative mini combined cycle suitable to meet the electric and thermal energy needs of the ship prime or auxiliary system. The objective is twofold. One aspect to be investigated is the repartition of the electric and thermal power and the evaluation of the electric and thermal efficiencies as a function of the main thermodynamic parameters related to the gas turbine top cycle limitations, the steam turbine bottom cycle and the steam requested for thermal use. The second aspect to be investigated is the range of electric and thermal power that a compact mini combined cycle 
can cover considering a basic single stage centrifugal compressor- uncooled centripetal turbine, compact architecture. Besides the naval applications on which the paper focus, the same combined cycle can also be used for equivalent land or off shore uses.

\section{Mini combined cycle with thermal cogeneration}

In this paper, a mini combined cycle, which consists of a simple Brayton cycle (topping) and a Hirn cycle (bottoming), is considered. The main components of the plant based on the considered combined cycle are a LNG-fuelled mini gas turbine, a single-pressure heat recovery steam generator and a small back pressure steam turbine, as shown in Figure 1.

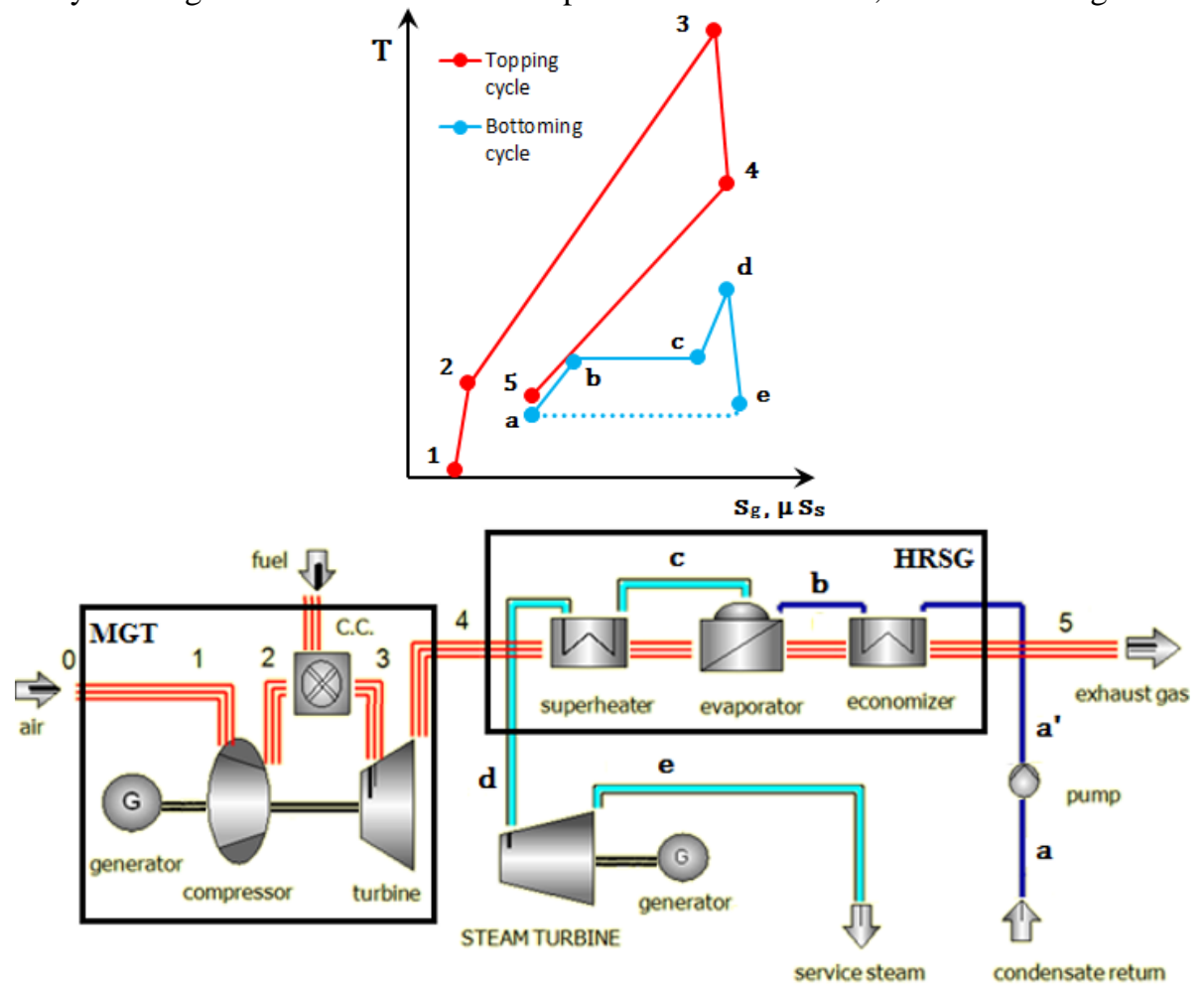

Fig. 1. Schematic representation of the cogeneration system

The mini gas turbine operates on the principle of the Brayton cycle. The working fluid, air, is drawn and compressed by a centrifugal compressor, then it is mixed with fuel and burned in the combustion chamber. The resulting hot gas expands through a centripetal turbine, which drives both the compressor and an electric generator. The heat contained in the exhaust gas exiting the mini gas turbine is used in the single-pressure HRSG to produce superheated steam. After being expanded to a pressure of 3 bar in the steam turbine, it is delivered to the ship's steam network covering the whole or part of the heat demand. Therefore, the steam cycle allows both to increase the production of electricity of the mini gas turbine plant and to generate superheated steam to be used as heat carrier to thermal users.

In order to evaluate the combined heat and power efficiency $\left(\eta_{c h p}\right)$, the thermal power $(\mathrm{H})$ generated by the plant has been considered to be equal to that the superheated steam exiting the turbine releases in a constant pressure cooling and condensation process up to the saturated liquid state. All the presented results have been obtained by means of the 
commercial power plant simulation software GE GateCycle ${ }^{\circledR}[10]$ adopting the assumptions that are reported in Table 1, unless otherwise stated.

Table 1. Main assumptions

\begin{tabular}{|c|c|c|c|}
\hline \multicolumn{2}{|l|}{ Considered LNG composition } & $\begin{array}{ll}\text { Compressor } & \text { mechanical } \\
\text { efficiency [\%] } & \end{array}$ & 98 \\
\hline Methane molar content [\%] & 97.5 & Combustor pressure losses [\%] & 3 \\
\hline Nitrogen molar content [\%] & 0.5 & TIT $\left[{ }^{\circ} \mathrm{C}\right]$ & 950 \\
\hline Ethane molar content [\%] & 1.8 & Combustion efficiency [\%] & 99 \\
\hline Propane molar content [\%] & 0.2 & Isentropic turbine efficiency [\%] & 90.5 \\
\hline \multirow[t]{2}{*}{ Calculated LHV [kJ/kg] } & $\begin{array}{c}4950 \\
4\end{array}$ & $\begin{array}{l}\text { Turbine mechanical efficiency } \\
\text { [\%] }\end{array}$ & 98 \\
\hline & & $\begin{array}{l}\text { Mini gas turbine generator } \\
\text { efficiency [\%] }\end{array}$ & 94 \\
\hline \multicolumn{2}{|l|}{ Ambient conditions } & HRSG hot side pressure drop [\%] & 3 \\
\hline Ambient temperature $\left[{ }^{\circ} \mathrm{C}\right]$ & 15 & HRSG thermal losses [\%] & 0.7 \\
\hline Ambient pressure [bar] & $\begin{array}{c}1.01 \\
3\end{array}$ & $\begin{array}{ll}\text { Sub-cooling } & \text { temperature } \\
\text { difference }\left[{ }^{\circ} \mathrm{C}\right] & \end{array}$ & 10 \\
\hline \multirow[t]{2}{*}{ Ambient humidity [\%] } & 60 & $\begin{array}{l}\text { Economizer cold side pressure } \\
\text { drop [\%] }\end{array}$ & 15 \\
\hline & & $\begin{array}{lll}\text { Pinch } & \text { point } & \text { temperature } \\
\text { difference } & {\left[{ }^{\circ} \mathrm{C}\right]} & \end{array}$ & 10 \\
\hline Assumptions & & $\begin{array}{l}\text { Superheater cold side pressure } \\
\text { drop [\%] }\end{array}$ & 8 \\
\hline $\begin{array}{l}\text { Mini gas turbine intake pressure } \\
\text { loss [\%] }\end{array}$ & 1 & $\begin{array}{l}\text { Steam turbine outlet pressure } \\
\text { [bar] }\end{array}$ & 3 \\
\hline $\begin{array}{l}\text { Isentropic compressor efficiency } \\
\text { [\%] }\end{array}$ & 84 & $\begin{array}{l}\text { Steam turbine } \\
\text { efficiency }[\%]\end{array}$ & 75.5 \\
\hline Compressor pressure ratio [-] & 6 & Pump isentropic efficiency [\%] & 83 \\
\hline
\end{tabular}

The main novelty of the proposed combined cycle is the small size of the turbomachineries used in the plant. The aim is to propose a combined heat and power system, characterized by a good electrical efficiency $\left(\eta_{e l}\right)$, high cogeneration efficiency and an adequate production of low pressure steam, within a plant size range where an optimal solution has not established yet.

To define the best operating parameters of the proposed combined cycle it is necessary to choose a desired compromise between the aforementioned objectives and to pay attention to comply with all the constraints the turbomachinery design, manufacturing and employed technologies impose. So to optimize the proposed combined cycle the main degrees of freedom are the pressure ratio $(\beta)$ of the Brayton cycle and the thermodynamic state $\left(p_{d}, T_{d}\right)$ of the steam produced in the HRSG.

Using a radial compressor composed of a single stage, the maximum obtainable pressure ratio is about 6 . It is well known that, lowering this parameter, the electrical efficiency of the mini gas turbine $\left(\eta_{e l, m g t}\right)$ decreases and, conversely, the exhaust gases temperature $\left(T_{4}\right)$ increases together with the specific thermal power $\left(P^{\prime}{ }_{t h a}\right)$, which can be exploited by the bottoming cycle. For example, according to the assumptions listed in Table 1, when the pressure ratio is increased from 4.5 to 6 , the mini gas turbine electrical efficiency increases from $20.9 \%$ to $23.9 \%$, while $T_{4}$ and the specific thermal power $P^{\prime}{ }_{\text {tha }}$ decreases from $627^{\circ} \mathrm{C}$ to $572{ }^{\circ} \mathrm{C}$, the former, and from $596 \mathrm{~kJ} / \mathrm{kg}$ to $531 \mathrm{~kJ} / \mathrm{kg}$, the latter. 
$\mathrm{T}_{\mathrm{d}}=400^{\circ} \mathrm{C} \rightarrow \mathrm{T}_{\mathrm{d}}=425^{\circ} \mathrm{C}-\because-\mathrm{T}_{\mathrm{d}}=450^{\circ} \mathrm{C} \cdots *-$

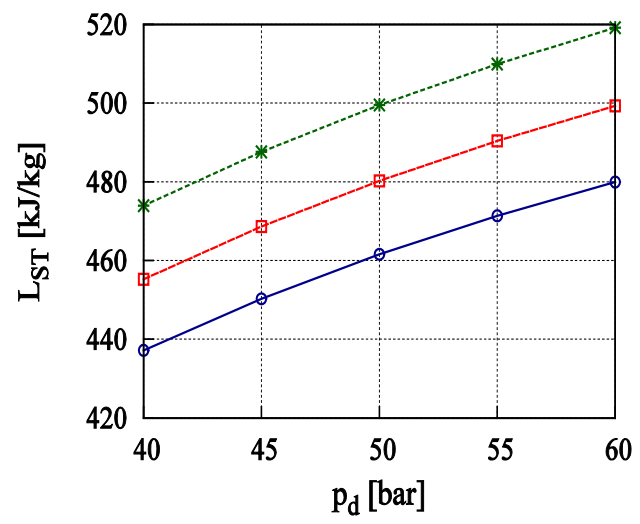

(a)

$\mathrm{T}_{\mathrm{d}}=400^{\circ} \mathrm{C} \rightarrow \mathrm{T}_{\mathrm{d}}=425^{\circ} \mathrm{C}-\mathrm{-}-\mathrm{T}_{\mathrm{d}}=450^{\circ} \mathrm{C}$

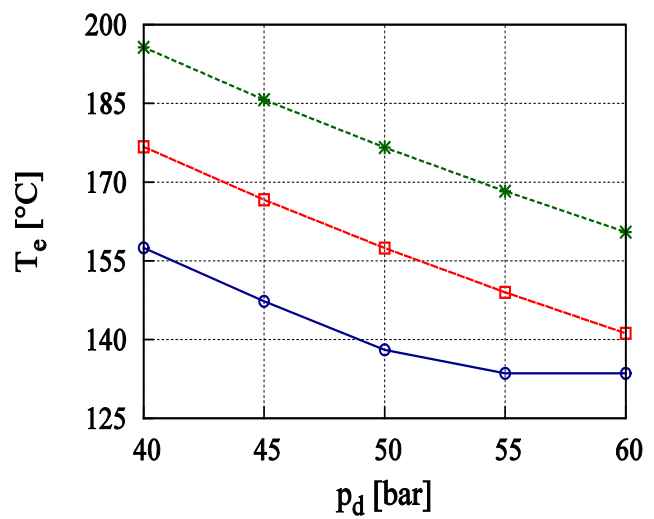

(c)
$\mathrm{T}_{\mathrm{d}}=400^{\circ} \mathrm{C} \rightarrow \quad \mathrm{T}_{\mathrm{d}}=425^{\circ} \mathrm{C}-\because-\mathrm{T}_{\mathrm{d}}=450^{\circ} \mathrm{C}-*$

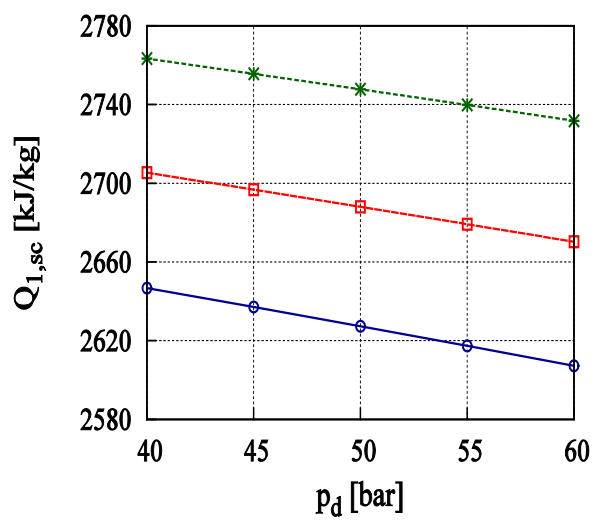

(b)

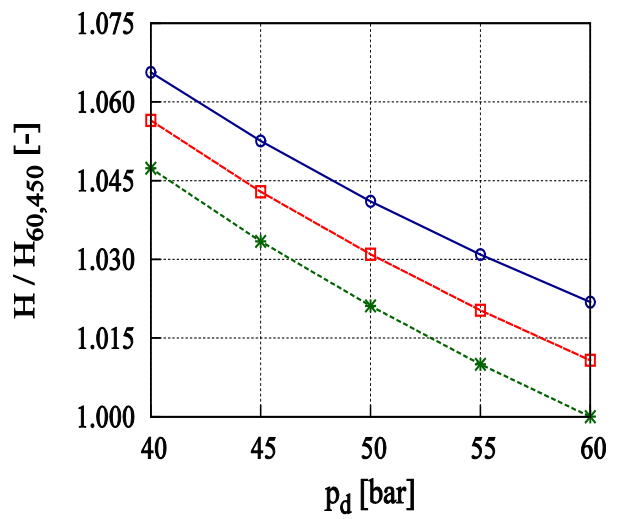

(d)

With regards to the steam cycle, similarly, it can be observed that if $p_{d}$ and $T_{d}$ are lowered from their maximum allowable values (60 bar and $450{ }^{\circ} \mathrm{C}$, respectively), which are dictated by steam turbine constructive features, the electrical efficiency of the combined plant diminishes, as a result of the reduction of the turbine specific work $L_{s t}$ (Figure 2a), but the cogeneration efficiency becomes higher, mainly thanks to the increase of the steam flow rate produced in the HRSG, due to the reduction of $T_{d}$, or the rise of the steam turbine outlet temperature $T_{e}$, as a result of the lower value of $p_{d}$. These remarks are clearly shown by Figure 2. The temperature and the pressure of the steam produced in the HRSG have an opposite effect on both the required heat to produce $1 \mathrm{~kg}$ of steam $\left(Q_{1, s c}\right)$ and the steam turbine outlet temperature $\left(T_{e}\right)$, but they influence the thermal power $(H)$, which is generated by the plant, in the same direction. Figure $2 \mathrm{~d}$ shows the trend of the thermal power with respect to $p_{d}$ and $T_{d}$, being $\mathrm{H}_{60,450}$ the value obtained for steam at 60 bar and $450{ }^{\circ} \mathrm{C}$. 
In light of this, two different mini combined cycle, which are later referred to as case A and $\mathrm{B}$, have been considered. The former, characterized by a mini gas turbine pressure ratio of 4.5 and a HRSG producing superheated steam at 40 bar and $400^{\circ} \mathrm{C}$, maximizes the thermal power, while the latter, with $\beta=6, p_{d}=60 \mathrm{bar}$ and $T_{d}=450^{\circ} \mathrm{C}$, maximizes the electrical power.

The influence of $\beta$ on the mini combined cycle performance (electrical efficiency $\eta_{e l}$, thermal efficiency $\eta_{t h}$, overall efficiency $\eta_{c h p}$, steam to air mass flow rate ratio $\Phi$, electricity to heat ratio $\mathrm{E} / \mathrm{H}$ and steam to gas turbine power ratio $\Psi$ ), for the steam turbine admission conditions of both case A and B, is shown in Figure 3. It is evident that the mini gas turbine pressure ratio is about twice more influential than the thermodynamic state of the steam produced in the HRSG.
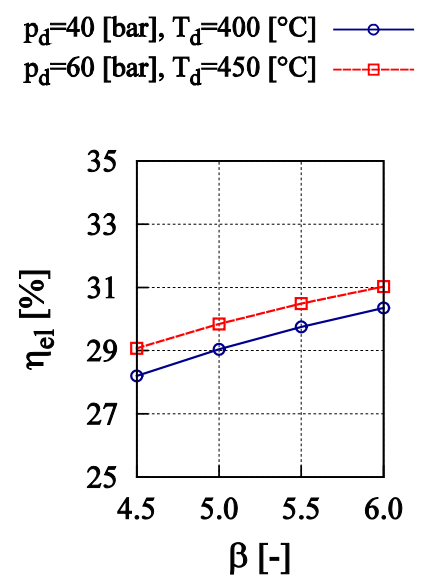

(a)

$\mathrm{p}_{\mathrm{d}}=40[\mathrm{bar}], \mathrm{T}_{\mathrm{d}}=400\left[{ }^{\circ} \mathrm{C}\right] \longrightarrow$ $\mathrm{p}_{\mathrm{d}}=60[\mathrm{bar}], \mathrm{T}_{\mathrm{d}}=450\left[^{\circ} \mathrm{C}\right]$

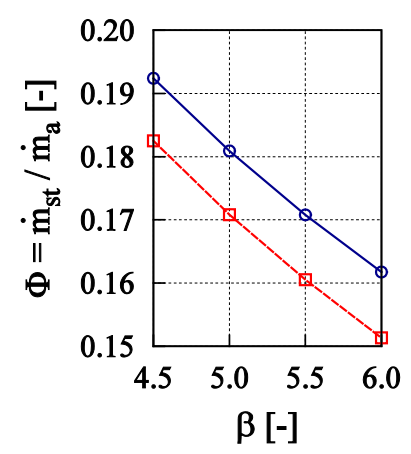

(d)

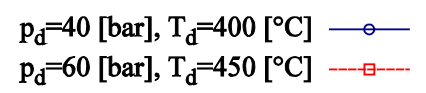

$\mathrm{p}_{\mathrm{d}}=40[\mathrm{bar}], \mathrm{T}_{\mathrm{d}}=400\left[{ }^{\circ} \mathrm{C}\right]$
$\mathrm{p}_{\mathrm{d}}=60[\mathrm{bar}], \mathrm{T}_{\mathrm{d}}=450\left[{ }^{\circ} \mathrm{C}\right]$

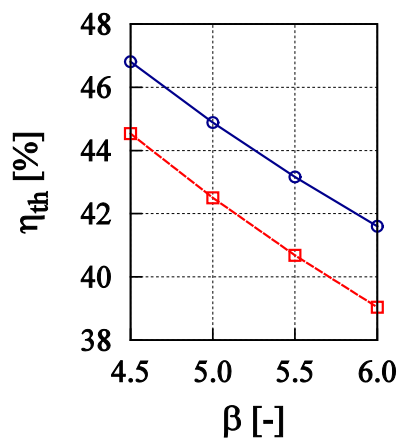

(b)

$\mathrm{p}_{\mathrm{d}}=40$ [bar], $\mathrm{T}_{\mathrm{d}}=400\left[{ }^{\circ} \mathrm{C}\right]$ $\mathrm{p}_{\mathrm{d}}=60$ [bar], $\mathrm{T}_{\mathrm{d}}=450\left[{ }^{\circ} \mathrm{C}\right]$

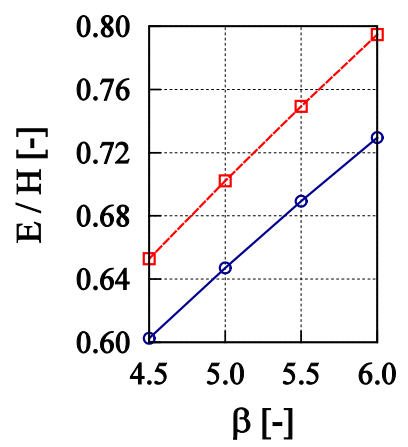

(e)

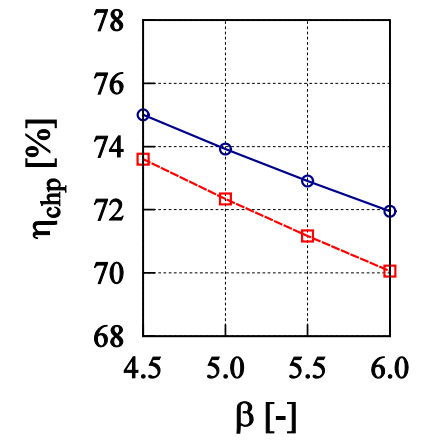

(c)

$\mathrm{p}_{\mathrm{d}}=40$ [bar], $\mathrm{T}_{\mathrm{d}}=400\left[{ }^{\circ} \mathrm{C}\right] \longrightarrow$

$\mathrm{p}_{\mathrm{d}}=60[\mathrm{bar}], \mathrm{T}_{\mathrm{d}}=450\left[{ }^{\circ} \mathrm{C}\right]$

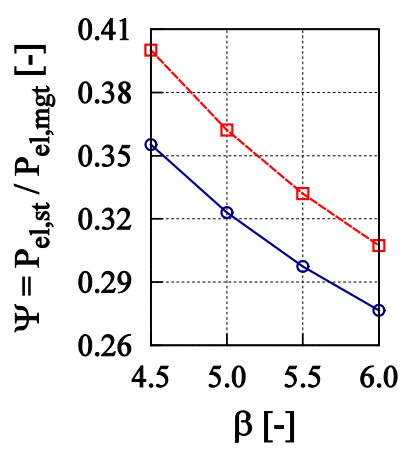

(f)

Fig. 3. Influence of $\beta$ on: (a) $\eta_{e l}$, (b) $\eta_{t h}$, (c) $\eta_{c h p}$, (d) $\Phi$, (e) $\mathrm{E} / \mathrm{H}$, (f) $\Psi$ for steam turbine admission conditions of case $\mathrm{A}\left(p_{d}=40 \mathrm{bar}, T_{d}=400^{\circ} \mathrm{C}\right)$ and $\mathrm{B}\left(p_{d}=60 \mathrm{bar}, T_{d}=450{ }^{\circ} \mathrm{C}\right)$ 
The performance of both the mini combined cycle A and B1, relating to a single unit that can supply an electrical power of $2 \mathrm{MW}$, are summarized in Table 2 . Higher energy demands can be met using a series of these mini-modules. For example, 3 or 4 of these modules may be sufficient to cover the electrical and thermal demands of a cruise ship in port docking without propulsion loads [3] [11].

In case of higher electrical demand, considering, for instance, also the propulsive power in the case of full electric ship propulsion, using the present basic cycle analysis, it is also possible to foresee a single module (CASE B2) that can supply an electrical power of $10 \mathrm{MW}$ along with around 20 tons per hour of 3 bar steam, reaching an electrical efficiency of 33\% and a combined heat and power efficiency of around $72 \%$ (see last column of Table 2). In this case, the power range is limited by technological and economical consideration related mainly on the growing of the frontal size of the compact single stage compressor - turbine radial architecture of the gas turbine system. As a rough engineering rule, to be further investigated in details, a diameter of $1 \mathrm{~m}$ for the radial turbomachinery rotors is considered to be an acceptable maximum radial dimension. In the following paragraph, the gas turbine dimensioning of the two extremes of the range investigated (namely, pressure ratio 4.5 and gas turbine power of 1.5 MW - CASE A- and pressure ratio 6 and gas turbine power $7.5 \mathrm{MW}$ - CASE B2).

Table 2. Performance of the two mini combined cycles, $\mathrm{A}\left(\beta=4.5, p_{d}=40 \mathrm{bar}, T_{d}=400{ }^{\circ} \mathrm{C}\right)$ and $\mathrm{B}\left(\beta=6, p_{d}=60 \mathrm{bar}, T_{d}=450^{\circ} \mathrm{C}\right)$

\begin{tabular}{lccc}
\hline \multicolumn{1}{c}{ Performance } & Case A & Case B1 & Case B2 \\
\hline Total electrical power [kW] & 2000 & 2000 & 10000 \\
Mini gas turbine electric power [kW] & 1483 & 1539 & 7504 \\
Steam turbine electric power [kW] & 527 & 473 & 2551 \\
Pump power consumption [kW] & 10 & 12 & 55 \\
Steam to gas turbine power ratio [-] & 0.36 & 0.31 & 0.34 \\
Combined cycle electrical efficiency [\%] & 28.2 & 31.0 & 33.6 \\
Thermal power [kW] & 3320 & 2517 & 11295 \\
Steam mass flow rate [kg/s] & 1.50 & 1.13 & 5.15 \\
Steam turbine outlet temperature [ $\left.{ }^{\circ} \mathrm{C}\right]$ & 157 & 161 & 148 \\
Combined cycle CHP efficiency [\%] & 75.0 & 70.1 & 71.6 \\
Combined cycle thermal efficiency [\%] & 46.8 & 39.1 & 38.0 \\
Air to steam mass flow rate ratio [-] & 5.20 & 6.61 & 6.72 \\
Electricity to heat ratio [-] & 0.60 & 0.80 & 0.89 \\
Fuel mass flow rate [kg/s] & 0.14 & 0.13 & 0.60 \\
Mini gas turbine exhaust mass flow [kg/s] & 7.93 & 7.61 & 35.17 \\
Mini gas turbine exhaust temperature [ $\left.{ }^{\circ} \mathrm{C}\right]$ & 627 & 572 & 568 \\
Stack temperature [ ${ }^{\circ} \mathrm{C}$ ] & 178 & 205 & 207 \\
\hline
\end{tabular}

\section{Gas turbine}

\subsection{Design process}

Gas turbine components design need the fulfilling of several steps. Starting from the requirements obtained from the cycle design, it is possible to obtain the preliminary design of the machines in terms of main dimensions, blade angles, rotational velocity and velocity triangles. All these parameters define the configuration of the machine and are strictly related to the target of obtaining a compact and efficient machine. The first target is achieved by employing radial configuration turbomachines, able to provide a high specific load and thus 
low number of stages (for this case only one stage), while the second target is achieved by employing good design practise, based on a literature review and previous design experiences.

Once obtained the first guess geometries for both centrifugal compressor and radial turbine, it is possible to optimize the geometrical configurations by employing CFD calculations, coupled with optimization procedures, able to efficiently investigate a large amount of possible geometries with the aim of individuating the one that best fit the targets of the design. These targets can be both aerodynamics, mechanical, or dimension and weight constrains. The optimization procedure requires a parametric management of the geometrical parameters in order to make automatic the procedure needed for CFD calculations (geometrical model generation, mesh generation). In the following paragraph all the steps required for the complete design process of the centrifugal compressor and the radial turbine are reported.

\subsection{Preliminary design}

The centrifugal compressor and the centripetal turbine first guess geometries, which are required by the optimization procedure, have been designed starting from a one-dimensional preliminary approach aimed at fulfilling the design duty with the best machine efficiency, taking also into account the mechanical limitations of the materials. In this first design step the main dimensions and blade angles have been found applying 1D equations, starting from statistical relationships and literature data to set the ranges for the main unknown design parameters. Among others, the literature source was constituted for compressor 1D design mainly by [12-18] and for the turbine 1D design by [19-22]. For the 1D design, in house developed codes have been utilized. For the present case, several combined cycle configurations are studied. In particular, two extreme cases are deeply analysed:

- A mini combined cycle with an electrical power of about $2 \mathrm{MW}$ and a thermal power of about 3.3 MW

- A mini combined cycle with an electrical power of about 10.2 MW and a thermal power of about 11.9 MW.

The first case requires, as explained in the combined cycle analysis, a gas turbine group with an electrical power of about $1.5 \mathrm{MW}$, while the second one, a gas turbine group with an electrical power of about 7.6 MW. The second case can be obtained with two solutions: a modular gas turbine group, composed by five small gas turbine producing $1.5 \mathrm{MW}$ of electric power, or with a single larger gas turbine, producing the entire amount of required power. For these two extreme cases, the main work parameters needed for preliminary design, are reported in Table 3.

Table 3. Global parameters for preliminary design

\begin{tabular}{lcc}
\hline & $\begin{array}{c}\text { Case A } \\
\text { (2 MW) }\end{array}$ & $\begin{array}{c}\text { Case B2 } \\
(\mathbf{1 0 ~ M W )})\end{array}$ \\
\hline Compressor mass flow rate $[\mathrm{kg} / \mathrm{s}]$ & 7.8 & 34.6 \\
Compressor pressure ratio $[-]$ & 4.5 & 6 \\
Compressor power $[\mathrm{kW}]$ & 1446 & 7988 \\
Turbine mass flow rate $[\mathrm{kg} / \mathrm{s}]$ & 7.93 & 35.2 \\
Turbine pressure ratio $[-]$ & 4.19 & 5.59 \\
Turbine power $[\mathrm{kW}]$ & 3116 & 16210 \\
\hline
\end{tabular}


From these parameters, by employing 1D in house developed codes, it is possible to obtain the main global parameters and geometrical dimensions for centrifugal compressor and for radial turbine. The main steps of preliminary design process are:

1) Identification of the specific speed value maximizing the aerodynamic efficiency of the machine from statistical data available from experiences (see 23). This step allows the evaluation of the rotational speed.

2) Literature analysis to determine relationships between dimensionless variables (such as loading coefficient, blade number and geometrical parameters) as a function of specific speed.

3) Once the main geometrical dimensions of the machine are defined by means of the previous set of equations, both the shroud and the hub lines describing the meridional channel have been obtained connecting the edge points with elliptical profiles. These profiles will be later optimised in order to reduce as much as possible the velocity overspeed at shroud radius, that may eventually induce boundary layer separation;

4) Impeller inlet and exit angles should now be set in order to satisfy the Euler equation by imposing the desired work exchange

5) Evaluation of flow deviation angle in order to properly set the first guess solution for impeller metallic angles

6) Vane inlet and exit diameters are again determined by means of statistical relations coming from literature

The whole geometrical dimensions and flow angles computed following the procedure described from point 1 to point 6 have been slightly adjusted in order to properly match the present boundary conditions, especially in terms of mass flow rate and work to be exchanged and in order to avoid high relative Mach number at impeller tip. The preliminary design of the whole machine here described has been used as starting point for the optimisation procedure described in the next sections. The results for centrifugal compressor and radial turbine for both CASE A and CASE B2 are presented in Table 4 and in Table 5 respectively.

Table 4. Centrifugal compressor main dimensions

\begin{tabular}{lll}
\hline & $\begin{array}{c}\text { Case A } \\
\text { (2 MW) }\end{array}$ & $\begin{array}{c}\text { Case B2 } \\
\text { (10 MW) }\end{array}$ \\
\hline Specific speed number & 0.747 & 0.76 \\
Rotation speed [rpm] & 27000 & 13000 \\
Axial length [m] & 0.171 & 0.37 \\
Impeller inlet hub radius [m] & 0.04 & 0.19 \\
Impeller inlet tip radius [m] & 0.126 & 0.32 \\
Impeller inlet relative hub angle [deg] & 33.7 & 61.5 \\
Impeller inlet relative tip angle [deg] & 65.5 & 72.2 \\
Impeller outlet radius [m] & 0.22 & 0.45 \\
Impeller outlet absolute angle [deg] & 76.3 & 77.5 \\
Diffuser blade height [m] & 0.022 & 0.05 \\
Diffuser inlet radius [m] & 0.24 & 0.49 \\
Diffuser outlet radius [m] & 0.374 & 0.765 \\
Impeller blade number & $12+12$ & $11+11$ \\
Diffuser blade number & 20 & 19 \\
\hline
\end{tabular}

Table 5. Radial turbine main dimensions

\begin{tabular}{lcc}
\hline & $\begin{array}{c}\text { Case A } \\
(\mathbf{2} \text { MW) }\end{array}$ & $\begin{array}{c}\text { Case B2 } \\
(\mathbf{1 0} \text { MW) }\end{array}$ \\
\hline Specific speed number & 0.489 & 0.525
\end{tabular}




\begin{tabular}{lll} 
Rotation speed [rpm] & 27000 & 13000 \\
Axial length [m] & 0.179 & 0.39 \\
Stator inlet radius [m] & 0.335 & 0.66 \\
Stator outlet radius [m] & 0.269 & 0.53 \\
Rotor inlet radius[m] & 0.262 & 0.51 \\
Rotor inlet relative angle [deg] & 0 & 0 \\
Rotor outlet mean radius [m] & 0.11 & 0.234 \\
Rotor outlet blade height [m] & 0.19 & 0.44 \\
Rotor outlet absolute hub angle [deg] & 0 & 0 \\
Rotor outlet absolute tip angle [deg] & 10 & 10 \\
Stator blade number & 14 & 13 \\
Rotor blade number & 19 & 17 \\
\hline
\end{tabular}

As one can observe, the preliminary design of the machines of CASE B2, obtained for pressure ratio 6 and gas turbine power 7.6 MW, leads to a diameter of about $1 \mathrm{~m}$ for the radial turbomachinery rotors $(0.9 \mathrm{~m}$ for the compressor and $1.02 \mathrm{~m}$ for the radial turbine), These values, as previously discussed, can be considered to be an acceptable maximum radial dimension.

\subsection{Optimization procedure}

The commercial software Numeca/Autoblade [24] has been employed to choose a proper set of parametric curves and to identify the most appropriate geometrical topology that enables the designer to manage different geometrical shapes via a limited number of key parameters. For achieving axial-to-radial configuration both hub and shroud contours present the same geometrical topology: an axial line part, followed by a Bezier curve with 4 control points, to end it up with another line, radially directed. For compressor main blade camber parameterization a Bezier curve, controlled by 5 points equally distributed along the abscissa, has been used for three spanwise sections. For half-thickness law definition, a Bezier curve with 4 control points has been adopted on each spanwise section. The diffuser row is made up of straight wedge-shaped blades. After imposing the required constraints, the compressor parametric geometrical model has 26 degrees of freedom. For the radial turbine, similarly to compressor parameterization, Bezier curves have been used for geometry representation, adopting in this case 22 free parameters. The geometrical parameterization of the two machines is reported in Figure 4.

Centrifugal compressor

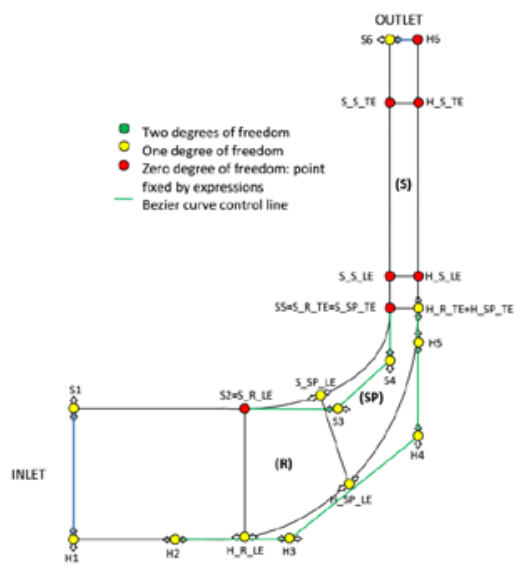

Radial turbine

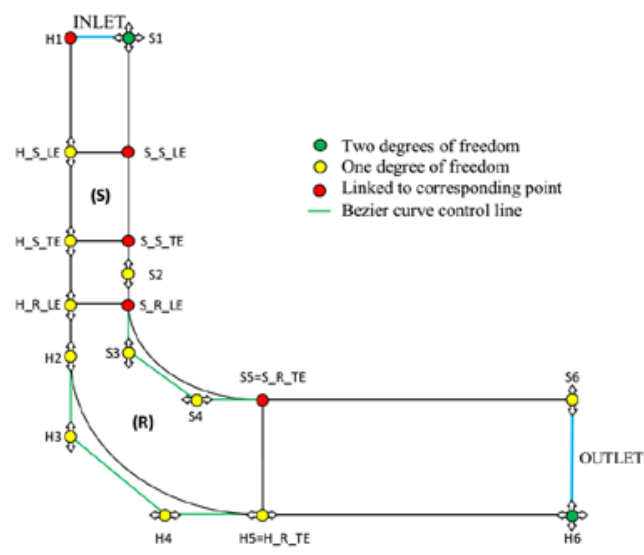

Fig. 4. Compressor and turbine geometrical parameterization 
The whole fluid domain has been meshed by means of Numeca/IGG Autogrid5. For each row involved, a multi-block hexahedral structured mesh is built. The entire mesh is made up of about 2 million and 1.5 million of cells for compressor and turbine, respectively. The CFD calculation is arranged throughout Numeca/FineTurbo and is carried out by means of Numeca/Euranus Navier Stokes equations solver. A RANS steady approach [25] has been used and the two equations SST (Shear Stress Transport) model [26-27] has been chosen for representing turbulence phenomenology. No slip boundary condition is assumed at solid walls and rotation periodicity condition is adopted to match periodic surfaces.

For the database generation, due to the high number of variables involved in the optimization process, a $25 \mathrm{X}$ and a $15 \mathrm{X}$ random sampling has been chosen for compressor and turbine, respectively. The optimization procedure is applied in order to minimize a single objective function that is composed by the sum of several dimensionless penalty terms. Each penalty term has a weighting coefficient. In the centrifugal compressor optimization the objective function is composed in order to maximize the total-to-total isentropic efficiency, to guarantee the design absolute total pressure ratio and an absolute subsonic flow condition at diffuser inlet. For radial turbine, the aim of the objective function is to drive the optimization process to ensure a mass flow rate equal to design condition, to keep the outlet tangential velocity in a desired range along spanwise direction (sampling the values on four spanwise sections), and to maximize the overall efficiency.

The optimization procedure above described has been employed to obtain the optimal geometries for both centrifugal compressor and radial turbine for the case with cycle pressure ratio of 4.5, as extensively reported in [28], [29] and [30]. The case relating to a pressure ratio of 6 it is currently being optimized, following the same procedure previously presented.

\section{Conclusions}

A compact mini combined cycle for naval applications has been designed with the aim of defining a cycle characterized by a good electrical efficiency, a high cogeneration efficiency, and an adequate production of low pressure steam, within a plant size range between 2 and 10 MWel.

The proposed basic mini-cycle consists of a gas turbine (GT), a heat recovery steam generator (HRSG), a steam turbine and a heat user which receive the steam at the pressure of 3 bar.

The design criterion has been based on the energy demands of the user, both electrical and thermal. In particular, the thermal requirement of the user has been adopted to set the steam flow rate to be processed by the steam turbine and therefore produced by the HRSG. Once the conditions of the steam at the inlet of the turbine have been chosen, the size of the HRSG and the flow rate of hot gases coming from the top cycle discharge have been determined.

Since the gas turbine inlet temperature is fixed by technological limit of the material and mechanical loading of the turbine rotor, the main degrees of freedom for the optimization of the proposed combined cycle are the pressure ratio of the Joule cycle and the thermodynamic state (i.e. pressure and temperature) of the steam produced in the HRSG to supply. To optimize the mini-cycle performance, simultaneously complying with the turbomachines constraints, a GT pressure ratio range from 4.5 to 6.0 and steam turbine range for the inlet temperature and pressure from $400^{\circ} \mathrm{C}$ and $450{ }^{\circ} \mathrm{C}$ and 40 and 60 bar, respectively, have been fixed.

The lower limit of all the thermodynamic parameters determines the maximum of the heat recovery power, while the upper limit represents the maximum electric power production condition.

Since the maximum demand of heat compared to electric power is required for ship docking condition and the maximum demand for electric power is required by the propulsion system, two 
extreme conditions have been considered the 2 MWel system with lower values for the thermodynamic parameters and the $10 \mathrm{MWel}$ with the higher values.

Once defined the overall characteristics of the mini combined plant, the paper focus on the preliminary design of the gas turbine unit and the procedures adopted have been shown.

Thanks to the combined cycle and the heat and power cogeneration concept adopted, the overall electrical efficiency range from about $28 \%$ to about $33 \%$, while a total return (thermal + electricity) of around $75 \%$ can be achieved.

Furthermore it has also been shown that, with the proposed mini cycle, a maximum power of about $10 \mathrm{MWel}$ can be achieved retaining the single stage centrifugal compressor - centripetal uncooled turbine, gas turbine compact configuration.

In case of larger electric power demand (for instance for propulsion purpose) a modular multiple gas turbine system combined with a larger HRSG and steam turbine can be employed with larger operational capabilities and even more efficiency.

\section{References}

1. M. Dzida, W. Olszewski, Polish Maritime Research, 18, 4, 43-48 (2011)

2. M. M. Elgohary, I. S. Seddiek, Journal of King Abdulaziz University, Marine Science. 23, 109-127 (2012)

3. B. N. Sanneman, Marine Technology and Sname News. 41, 161-166 (2004)

4. F. Haglind, Energy Conversion and Management. 49, 3458-3467 (2008)

5. F. Haglind, Energy Conversion and Management. 49, 3468-3475 (2008)

6. F. Haglind, Energy Conversion and Management. 49, 3476-3482 (2008)

7. M. Altosole, G. Benvenuto, U. Campora, M. Laviola, R. Zaccone, Design and Simulation of Combined Gas Turbine-Steam or Diesel-Steam Plants for Marine Applications, in proc. of the $12^{\text {th }}$ International Symposium on Experimental Computational Aerothermodynamics of Internal Flows (Lerici, 2015)

8. C. Salvini, A. Giovannelli, M. Varano, International Journal of Heat and Technology, 34, 443-445 (2016)

9. J. D. Brostmeyer, US Patent 8,640,437 (2014)

10. GateCycle 6.1.1 User's Guide, GE Enter software for Windows version [Electronic resource] Access Mode: www.gepower.com (2005)

11. A. Armellini, S. Daniotti, P. Pinamonti, M. Reini, Applied Energy, 211, 306-317 (2018)

12. N. A. Cumpsty, Compressor aerodynamics (Longman Scientific \& Technical, 1989)

13. P. H. Rothe, J.P. Johnston, Journal of Fluids Engineering, 98, 3, 422-429 (1976)

14. J. Moore, Journal of Engineering for Power, 95, 3, 205-219 (1973).

15. M. Casey, F. Gersbach, C. Robinson, An optimization technique for radial compressor impellers in Proc. of ASME Turbo Expo, 2401-2411 (Berlin, 2008).

16. D. Eckardt, Journal of Fluids Engineering 98, 3, 390-399 (1976)

17. H. Krain, Journal of turbomachinery 110.1, 122-128 (1988)

18. Y. Wang, K. Wang, Z. Tong, F. Lin, C. Nie, A. Engeda, Journal of Thermal Science, 22, 5, 404-412 (2013)

19. A. Whitfield, N. C. Baines, Design of radial turbomachines (1990)

20. H. E. Rohlik, Radial-inflow turbines, in Glassmann A J (ed) turbine design and application, NASA SP 290, 3 (1975) 
21. H. Chen, N. C. Baines, Procs of the Institution of Mechanical Engineers, Part A: Journal of Power and Energy, 206, 3, 177-187 (1992)

22. G. D. Cox, C. Fischer, M. V. Casey, The application of throughflow optimisation to the design of radial and mixed flow turbines, 9th International Conference on Turbochargers and Turbocharging, 217-226 (19 May 2010-20 May 2010, London)

23. E. A. Baskharone, Principles of Turbomachinery in Air Berating Engines (Cambridge University Press, 2006)

24. NUMECA, User manuals. Academic R\&D license (2018).

25. C. Hirsch, C. Lacor, A. Rizzi, P. Eliasson, I. Lindblad, J. Haeuser, A multiblock/multigrid code for the efficient solution of complex 3D Navier-Stokes flows in Aerothermodynamics for Space Vehicles SEE N92-14973 06-02, 415-420 (1991)

26. J.A. Bourgeois, R.J. Martinuzzi, E. Savory, C. Zhang, D.A. Roberts, J. Turbomach., 133 (1): 011025 (2010)

27. L. Mangani, E. Casartelli, S. Mauri. ASME. Conference Paper in J. Turbomach., 134 (6), 2219-2229 (2012)

28. D. Barsi, A. Perrone, L. Ratto, D. Simoni, P. Zunino, Radial inflow turbine design through Multidisciplinary optimization technique in ASME Turbo Expo 2015: Turbine Technical Conference and Exposition, 8 (2015)

29. A. Perrone, L. Ratto, G. Ricci, F. Satta, P. Zunino, Multi-Disciplinary Optimization of a Centrifugal Compressor for Micro-Turbine Applications in ASME Turbo Expo 2016: Turbomachinery Technical Conference and Exposition, 8 (2016)

30. D. Barsi, A. Perrone,Y. Qu, L. Ratto, G. Ricci, V. Sergeev, P. Zunino, Journal of Thermal Science 27(3), 259-269 (2018) 